\title{
Práticas educativas e problemas de comportamento: uma análise à luz das habilidades sociais
}

\author{
Alessandra Turini Bolsoni-Silva \\ Universidade Estadual Paulista \\ Edna Maria Marturano
}

Universidade de São Paulo

\begin{abstract}
Resumo
Este artigo tem por objetivo analisar as relações entre práticas educativas dos pais e problemas de comportamento dos filhos, à luz do referencial teórico-prático do treinamento em habilidades sociais. A forma como os pais educam seus filhos parece ser crucial à promoção de comportamentos socialmente adequados, porém, com frequiência, as famílias acabam estimulando comportamentos inadequados por meio de disciplina inconsistente, pouca interação positiva, pouco monitoramento e supervisão insuficiente das atividades da criança. Considera-se que os pais, para promoverem comportamentos adequados em seus filhos, necessitam ter habilidades sociais educativas, tais como expressar sentimentos e opiniões, estabelecer limites evitando coerção, entre outras. Conclui-se que, intervenções com pais, com a finalidade de promover habilidades sociais educativas, são importantes meios para prevenção e redução de problemas de comportamento em crianças, de forma a evitar dificuldades escolares e de socialização na meninice e na adolescência.
\end{abstract}

Palavras-chave: Relacionamento pais-filhos, Prática educativa, Problemas de comportamento, Habilidades sociais, Prevenção.

\begin{abstract}
Educational practices and problem behavior: An analysis from the point of view of social skills. The aim of this article is to analyze the relationships between parenting rearing practices and child behavior problem, from the point of view of the theoretical and practical foundations of social skills training. The way parents socialize their children seems to be crucial for the promotion of socially appropriate behaviors, but families frequently come to inadvertently stimulate inadequate behavior through inconsistent discipline, low levels of positive interaction, poor monitoring and insufficient supervision. It is argued that to promote appropriate child behaviors it is necessary for parents to have abilities proper of parenting rearing practices such as to express feelings and opinions, and to set limits whereas avoiding punishment. It is concluded that parent training interventions aimed at developing educational social skills are important tools for prevention and reduction of child problem behavior, as a means to prevent academic and social difficulties in childhood and adolescence.
\end{abstract}

Key words: Parent-child relationship, Educational practice, Problem behavior, Social skills, Prevention.

A forma como os pais interagem e educam seus filhos é crucial à promoção de comportamentos socialmen te adequados ou de comportamentos considerados, pelos pais e/ou professores, como inadequados, os quais são entendidos como "déficits ou excedentes comportamentais que prejudicam a interação da criança com pares e adultos de sua convivência" (Silva, 2000, p. 1).

Ao analisar trabalhos de Patterson, DeBaryshe e Ramsey (1989), CID-10 (1993), Brioso e Sarrià (1995), Sidman (1995), Conte (1997), Kaiser e Hester (1997), Kaplan, Sadock e Grebb (1997), Ingberman (1997), Webster-Stratton (1997) e Del Prette e Del Prette (1999), é possível identificar muitos determinantes para problemas de comportamento. Estes pesquisadores apontam para a existência de uma ligação entre práticas educativas e comportamento anti-social dos filhos, à medida que as famílias estimulam estes comportamentos por meio de disciplina inconsistente, pouca interação positiva, pouco monitoramento e supervisão insuficiente das atividades da criança. Os pais tendem a ser não contingentes no uso de reforçamento positivo para comportamentos pró-sociais (ignorando-os ou respondendo de forma inapropriada) e empregam frequientemente punições para comportamentos desviantes (conceitos descritos adiante). Conseqüentemente, comportamentos coercitivos são diretamente reforçados pelos membros da família, 
levando a criança a utilizá-los, possivelmente, para sobreviver neste sistema social aversivo. Além disso, os filhos expostos à

violência por longos períodos, freqüentemente comportam-se de forma agressiva e, quando são criados em condições negligentes, tornam-se pouco tolerantes à frustração, com pouca motivação para seguirem normas sociais e relativamente imunes ao remorso. Assim, estas crianças, ao ingressarem no ambiente escolar, passam a repetir este padrão, que, somando-se às dificuldades dos professores em lidar com as mesmas, faz com que comportamentos inadequados persistam, prejudicando a aprendizagem e a socialização. Afinal, dificuldades de aprendizagem e problemas de comportamento são duas variáveis bidirecionais, isto é, são causas e efeitos simultaneamente, havendo uma co-ocorrência entre elas (Marturano, Linhares \& Parreira, 1993; Trivelatto \& Marturano, 1999; Webster-Stratton, 1997).

Além disso, para Patterson, DeBaryshe e Ramsey (1989), existe uma seqüência desenvolvimentista acerca do comportamento anti-social, o qual seria iniciado por comportamentos perturbadores na infância até atingir a delinquiência no período da adolescência. Isto aconteceria frente a soma de alguns fatores, como rejeição parental e fracasso acadêmico da criança, o que a levaria a aproximar de grupos desviantes com risco para a delinqüência.

Webster-Stratton (1997) descreve uma progressão desenvolvimentista para problemas de comportamento, a qual pode assumir dois caminhos. O primeiro, chamado de early starter descreveria comportamentos agressivos e opositivos, no período inicial da pré-escola, podem progredir para agressividade e sintomas de problemas de comportamento na meninice, os quais podem se desenvolver para sintomas mais sérios na adolescência, tais como violência interpessoal e violações de propriedade. Os locais de ocorrência dos comportamentos perturbadores podem aumentar com o passar do tempo, ou seja, de casa ou pré-escola para locais escolares e finalmente comunidade mais ampla. A segunda possibilidade, denominada late starter, ao contrário, considera os casos que surgem na adolescência. O prognóstico parece ser, para esta autora, mais favorável para os casos que se encaixam na segunda hipótese do que para adolescentes que apresentaram uma história crônica de problemas de comportamento (Webster-Stratton, 1997).

Frente a esta problemática, o presente trabalho tem por finalidade analisar possíveis relações entre práticas educativas de pais e problemas de comportamento de filhos, bem como implicações à prevenção e/ou remediação de problemas de comportamento, por meio do esquema conceitual que orienta o campo teórico-prático do treinamento em habilidades sociais (THS)

\section{Campo teórico-prático do Treinamento em Habilidades Sociais (THS)}

O estudo do campo teórico-prático do THS é importante, segundo Caballo (1997), porque os seres humanos passam a maior parte de seu tempo engajados em alguma forma de co- municação interpessoal e, ao serem socialmente habilidosos, são capazes de promover interações sociais satisfatórias. Embora não haja consenso quanto à definição de habilidades sociais (HS), o termo HS geralmente é usado para designar um conjunto de capacidades comportamentais aprendidas que envolvem interações sociais (Caballo, 1995; Del Prette \& Del Prette, 1999). Para Del Prette e Del Prette (1999), as HS abrangem relações interpessoais, incluindo a assertividade (expressão apropriada de sentimentos negativos e defesa dos próprios direitos) e as habilidades de comunicação, de resolução de problemas interpessoais, de cooperação e de desempenhos interpessoais nas atividades profissionais.

A origem do movimento das habilidades sociais é freqüentemente atribuída a Salter (1949), considerado um dos pais da terapia comportamental, o qual promoveu técnicas para aumentar a expressividade verbal e facial, descritas em seu livro Conditioned Reflex Therapy. Em 1958, Wolpe utilizou pela primeira vez o termo "comportamento assertivo", referindo-se à expressão de sentimentos negativos e defesa dos próprios direitos (Caballo, 1996).

O termo habilidades sociais é tido, muitas vezes, erroneamente como sinônimo de assertividade, pois, segundo Del Prette e Del Prette (1999), o campo do THS é mais amplo e promove resolução de problemas, habilidades de comunicação, além de expressão de sentimentos negativos e defesa dos próprios direitos. Porém, apesar desta distinção, os termos são comumente utilizados como sinônimos (Caballo, 1996; Del Prette \& Del Prette, 1999; Falcone, 1998).

Comportamento socialmente habilidoso ou mais adequado refere-se à expressão, pelo indivíduo, de atitudes, sentimentos (positivos e negativos), opiniões, desejos, respeitando a si próprio e aos outros, existindo, em geral, resolução dos problemas imediatos da situação e diminuição da probabilidade de problemas futuros (Caballo, 1996). Comportamento socialmente habilidoso implica nas seguintes capacidades: iniciação e manutenção de conversações; falar em grupo; expressar amor, afeto e agrado; defender os próprios direitos; solicitar favores; recusar pedidos; fazer e aceitar cumprimentos; expressar as próprias opiniões, mesmo os desacordos; expressar justificadamente quando se sentir molestado, enfadado, desagradado; saber se desculpar ou admitir falta de conhecimento; pedir mudança de comportamento do outro e saber enfrentar as críticas recebidas (Caballo, 1996). As situações em que estas respostas podem ocorrer são muitas e variadas, como, por exemplo, ambientes familiares, de trabalho, de consumo, de lazer, de transporte público, de formalidade etc. É comum, em THS, o esclarecimento quanto a formas de se comportar, analisando as consequiências para a resolução de problemas e relacionamento interpessoal.

Por exemplo Alberti e Emmons (1978) diferenciam comportamento assertivo, não assertivo e agressivo. Assertividade é o processo pelo qual o indivíduo expressa sentimentos, pensamentos de forma adequada, ou seja, utiliza entonação, latência e fluência de fala apropriadas; ouve o interlocutor para então responder, de forma a atingir seus objetivos sem prejudicar as relações futuras com o mesmo 
(Alberti \& Emmons, 1978; Caballo, 1987). Não-assertividade ocorre quando a pessoa não expressa seus sentimentos ou seus pensamentos ao interlocutor, emitindo, muitas vezes, comportamentos contra a própria vontade, ou deixando de defender-se por medo de prejudicar sua relação futura com o interlocutor. Por isso, muitas vezes, o indivíduo é explorado e prejudicado sem contudo, atingir seus objetivos. A nãoassertividade nega e inibe a expressão de sentimentos, levando a pessoa a sentir-se ferida, ansiosa e autodesvalorizada e, por conseqüência, raramente atinge os objetivos desejados. Já a agressividade, às vezes, permite atingir os objetivos desejados, mas no processo o emissor magoa os demais, fazendo escolhas por eles, além de os desvalorizar como pessoas, possibilitando represálias futuras. Por outro lado, o comportamento assertivo permite a auto-apreciação do emissor e uma expressão honesta de seus sentimentos, geralmente atingindo os objetivos desejados, não prejudicando a si mesmo, nem o receptor.

Comportamentos assertivos, não-assertivos e agressivos podem ser gerais ou situacionais, isto é, há pessoas que possuem sempre ou a maior parte do tempo o mesmo padrão de comportamento, enquanto que outras, dependendo da situação e/ou do interlocutor, emitem comportamentos de natureza distinta. Assim, um adulto pode se comportar de forma não-assertiva em situação de trabalho (por não saber enfrentar assertivamente o chefe e temer o desemprego) e agressiva ao chegar em casa (porque, por exemplo, a esposa e filhos não vão reagir como o chefe poderia fazer e, também, como esta pessoa não expressou, durante todo dia, vários sentimentos e opiniões, chega um momento em que acaba sendo agressiva, por vezes, com o interlocutor errado).

Com base nesta breve descrição sobre o campo teóricoprático do treinamento em habilidades sociais, pretende-se tecer considerações acerca de práticas educativas de pais quanto às habilidades sociais aplicáveis à educação de filhos (HSE) à luz das habilidades sociais. Silva (2000) define HSE como "[o] conjunto de habilidades sociais (HS) dos pais aplicáveis à prática educativa dos filhos, por exemplo a HSE de [estabelecer] limites pode envolver várias habilidades sociais, tais como dizer não, pedir mudança de comportamento, além de componentes não-verbais e paralingüísticos" (p. 1).

\section{Habilidades Sociais Educativas (HSE)}

O conhecimento do campo do THS ajuda a compreender vários aspectos da relação pais-filhos e das práticas educativas, entre eles: a) o desempenho interpessoal está relacionado com suas auto-regras; b) a forma de compreensão dos próprios papéis e os do outro interferem na manutenção de relações positivas entre pais e filhos; c) a assertividade pode ser necessária para a manutenção de diálogos entre pais e filhos e resolução de problemas de forma positiva e efetiva; d) assegurar a aprendizagem social pode melhorar as relações entre os membros da família; e) a leitura do ambiente social (a escolha do melhor momento para a expressão, em geral quando o interlocutor estiver disponível para ouvir) favorece a percepção adequada do mesmo e pode ser apren- dida e f) a expressão de sentimentos positivos auxilia na formação de autoconceito satisfatório da criança.

Os pais, para promoverem comportamentos adequados em seus filhos, necessitam comportarem-se de forma socialmente adequada, isto é, sendo socialmente habilidosos ao invés de agressivos e/ou não-assertivos, a fim de promover a competência social daqueles. O termo competência social (CS) é utilizado em um sentido avaliativo, visando qualificar o nível de proficiência com que os comportamentos são ou deveriam ser emitidos diante de certa tarefa (McFall, 1982 e Del Prette \& Del Prette, 1996). Segue-se uma análise de como as habilidades sociais podem influenciar na prática educativa de pais e no repertório comportamental de filhos.

Silva (2000) afirma que a HSE dialogar com os filhos é muito importante no contexto educativo, pois refere-se ao repertório inicial para o desenvolvimento de todas as demais HSE, tais como fazer perguntas, expressar sentimentos, expressar opiniões e estabelecer limites. Estas HSE auxiliam os pais a transmitir padrões, valores e normas de comportamento da cultura para os filhos, o que, segundo Biasoli-Alves (1994), faz parte do papel da família, enquanto primeiro ambiente socializador da criança.

Autores (por exemplo Caballo, 1996 e Del Prette e Del Prette, 1999) do THS consideram a expressão de sentimentos de agrado e desagrado, especialmente de forma espontânea, como essenciais para a promoção de relacionamentos interpessoais satisfatórios. Conforme Silva (2000), os pais que expressam espontaneamente sentimentos positivos e negativos em relação aos comportamentos dos filhos os estão ajudando a discriminar comportamentos considerados como positivos, por eles e possivelmente pela sociedade, e também os considerados inadequados, facilitando, assim, que os filhos aprendam qual padrão comportamental é esperado, aumentando a probabilidade de aumentar a freqüência de comportamentos adequados e de reduzir inadequados (precursores de problemas de comportamento). Neste ponto, cabe ressaltar a não pretensão de que estas habilidades parentais tornem os filhos "cordeirinhos" frente à sociedade. Ao contrário, os pais servem de modelos e devem incentivar comportamentos assertivos dos filhos, quanto à expressão de sentimentos, opiniões e críticas.

Entretanto, para uma educação efetiva e relacionamento positivo entre pais e filhos não basta expressar os sentimentos, é preciso que os pais o façam de maneira socialmente adequada, ou seja, apontando, no caso de sentimentos negativos, qual o comportamento de que não gostaram, dizendo o que sentiram frente ao comportamento da criança e sugerindo alternativas para que se comporte de forma mais adequada, sem, contudo, valerem-se de acusações do tipo "você não tem consideração" ou "você é uma criança má", que interferem na auto-estima da criança e prejudicam as interações pais-filhos, pois funcionam como punições.

Os pais também podem utilizar estratégias educativas, diante de comportamentos inadequados dos filhos, as quais priorizam a expressão de opiniões e a solicitação adequada de mudança de comportamento, como por exemplo “... eu não 
gostei do que você fez (expressão de sentimento, apontando o comportamento da criança), eu prefiro que você se comporte desta outra maneira (expressão de opinião e solicitação específica de mudança de comportamento) para que possamos nos entender melhor (possível conseqüência positiva frente à mudança comportamental da criança).

No entanto, os pais tendem a agir coercitivamente quando estabelecem limites e/ou expressam opiniões. Evitar o uso de punições na educação dos filhos já foi assunto bastante discutido por diversos autores (entre eles, Skinner, 1953/1993; Sigolo,1986; Biasoli-Alves,1994 e Sidman, 1995). Skinner (1953/1993) e Sidman (1995) apontam a existência de três maneiras de controlar comportamentos: reforçamento positivo, reforçamento negativo e punição, sendo o primeiro não coercitivo e os demais, coercitivos. O reforço positivo ocorre quando a ação de uma pessoa é seguida pela adição de uma conseqüência que aumenta a probabilidade de ocorrência do comportamento ao qual for contingente. $\mathrm{O}$ reforço negativo, ao contrário, surge quando o indivíduo, ao se comportar, retira ou elimina algo desagradável de seu ambiente, ocorrendo, também, desta forma, uma probabilidade de aumento da frequiência posterior daquele comportamento. A punição, conforme Sidman (1995), ocorre de duas formas: perda de reforçadores positivos ou produção de reforçadores negativos.

A punição (Skinner, 1953/1993), enquanto técnica educativa, é questionável, pois a longo prazo, ao contrário do reforço positivo, traz desvantagens tanto para o organismo punido como para a agência punidora, gerando emoções negativas e predisposições para fugir ou contra-controlar. Para Skinner, a punição pode reduzir o comportamento punido de forma imediata, mas esse resultado não se mantém a longo prazo. Skinner (1953/1993) afirma que a punição pode fazer com que a criança pare imediatamente de emitir o comportamento punido (o que estimula os pais a continuarem punindo), porém pode eliciar sentimento de medo frente a situações similares à que foi punida, podendo levá-la a "fazer qualquer outra coisa" para fugir da punição. No entanto, estes efeitos do procedimento não garantem que o comportamento punido deixe de ocorrer na ausência da punição ou do agente punidor, suprimindo apenas temporariamente o comportamento punido.

Skinner (1953/1993) identifica lamentáveis subprodutos do uso de punições, tais como medo, ansiedade, culpa e doenças "psicossomáticas" ou outras que prejudicam a vida cotidiana do indivíduo, tais como falta de repertório socialmente adequado, que lhe permita resolver problemas e manter relacionamentos positivos. Estas consequiências são indesejáveis e devem ser evitadas, porém os pais, muitas vezes, devido a sua história de vida e repertório comportamental adquirido, não conseguem se relacionar com seus filhos de outra forma, o que justifica a necessidade de intervenções para pais que os auxiliem a desenvolver HSE alternativas para educar mais efetivamente e positivamente seus filhos. Sidman (1995) afirma que os pais interagem mais com seus filhos nos momentos de corrigir ou criticar e, conseqüentemente, a famí- lia está expondo o modelo coercitivo às suas crianças, as quais aprendem a utilizá-lo sempre que desejam que outros façam o que querem.

Skinner (1953/1993) e Sidman (1995) sugerem alternativas ao uso de punição. Uma delas é o processo de extinção, em que, por exemplo, os pais retiram a atenção de um comportamento inadequado do filho e este deve diminuir a freqüência de ocorrência, podendo chegar próximo de zero. Outra alternativa é usar, simultaneamente à extinção, reforçamento positivo para aumentar ou instalar comportamentos incompatíveis com aqueles indesejáveis. Estas técnicas podem ser usadas após a realização de análises funcionais, de forma a avaliar e compreender o porquê da criança comportar-se inadequadamente.

Certamente as crianças não vão passar a se comportar adequadamente (desejo dos pais) através do uso de coerção, ao contrário, a aquisição de "bons" comportamentos deve ocorrer diante do uso de reforçamento positivo. Por exemplo, se uma criança é punida por dizer aos pais que fez algo considerado errado, é possível que da próxima vez que os pais lhe perguntarem sobre se agiu correta ou incorretamente, ela vá mentir para evitar ser coagida. $\mathrm{O}$ uso de punições, como os pesquisadores afirmam, além de não resolver os problemas de comportamento, leva a ressentimentos e a dificuldades na interação entre pais e filhos, comprometendo o relacionamento de amizade e cooperação que deveria ocorrer, além de favorecer o surgimento de problemas na vida adulta e mesmo infantil, tais como baixa auto-estima, baixa autoconfiança e pouca flexibilidade comportamental frente às dificuldades encontradas no cotidiano.

Com base nas reflexões de Skinner (1953/1993) e Sidman (1995) é possível dizer que não basta informar os pais sobre quais métodos educativos são mais efetivos e positivos, é preciso instrumentalizá-los para que possam estabelecer limites necessários com o mínimo de punições, prevenindo e/ou resolvendo problemas de comportamento sem prejudicar o relacionamento interpessoal com seus filhos. O bom relacionamento entre os membros familiares envolve equilíbrio de reforçadores, valores, respeito, expressão de sentimentos, opiniões, cooperação e amizade. Equilíbrio de reforçadores é definido por Del Prette, Del Prette e Branco (1992) como condição para a existência de competência social (CS), pois, para haver competência, o indivíduo necessita se comportar em relação a seu interlocutor, equilibrando reforçadores ou, pelo menos, garantindo os direitos humanos básicos.

“Cumprir promessas" também é uma HSE importante, pois os pais, ao prometerem e não cumprirem, fazem com que os filhos sintam-se enganados, prejudicando o relacionamento pais-filhos. Por outro lado, os pais, ao cumprirem as promessas, estão servindo de modelo aos filhos, os quais provavelmente reproduzirão tal habilidade, além de aumentarem sua confiança no relato dos pais (Silva, 2000).

HSE, próprias do relacionamento pais-filhos, referem-se ao entendimento do casal quanto à educação do filho e a participação de ambos os progenitores na divisão de tarefas educativas (Silva, 2000). A autora verificou que, quando os 
pais possuíam tais HSE, a freqüência de problemas de comportamento em seus filhos era menor e a de comportamentos socialmente adequados, maior, sugerindo que a consistência nas práticas educativas também promove comportamentos socialmente adequados, ao mesmo tempo que previne problemas de comportamento. No entanto, se o casal concordar que a prática será prioritariamente punitiva, então a criança, provavelmente, não estará livre de desenvolver problemas de comportamento e/ou um quadro depressivo.

As HSE de "dizer não", "negociar" e de "estabelecer regras" também são importantes no que se refere à HSE mais ampla de estabelecer limites. Os pais necessitam aprender a dizer não para pedidos não razoáveis dos filhos, isto é, os pais necessitam estar atentos quanto à análise do pedido, a fim de verificar se realmente não é razoável, pois, se for, podem negociar com os filhos, de forma que ambas as partes cedam em algo. É importante que o pai e a mãe concordem, pois se o pai insistir no não, mas a mãe realizar o pedido ou vice-versa, o filho aprenderá o que deve pedir para cada um dos progenitores, de forma a conseguir o que deseja. Desta forma, fica claro que os pais necessitam conversar quanto à prática educativa, afinal tiveram, provavelmente, modelos distintos de como educar, sendo possível que tenham diferentes formas de lidar com os filhos.

A HSE de estabelecer regras é também essencial, pois os pais precisam pedir tarefas para os filhos de forma que sejam capazes de cumprir conforme a idade e as habilidades que possuem. Para tal, os pais necessitam adequar a fala à compreensão dos filhos de forma a garantir a compreensão, a qual pode ser assegurada se as regras forem aplicadas uma de cada vez, especialmente para crianças pequenas, elogiando-as cada vez que as cumpram adequadamente. Com o tempo, as regras podem ser mais frequientes e em maior número. Se a regra não for cumprida, os pais podem conversar assertivamente e verificar o porquê do não cumprimento, repetindo a regra quando necessário. (Silva, 2000; Becker, 1974)

Finalmente, a HSE de "desculpar-se" com os filhos necessita ser considerada. Os pais, ao pedirem desculpas, estão admitindo os próprios erros e ensinando os filhos a comportarem-se de forma parecida, o que é desejo dos pais. No entanto, Silva (2000) observou, em seus dados, que os pais têm receio de admitir os próprios erros aos filhos, temendo que estes deixem de respeitá-los e percam noções de limites. Desta forma, poucos pais relataram pedir desculpas a seus filhos, apesar de sentirem muita culpa e comportarem-se de forma a aliviar este sentimento, por exemplo, beijando o filho enquanto dorme. Tal resultado mostra a influência de regras culturalmente aceitas, tais como a de que os pais devam manter certo distanciamento dos filhos, para que estes "não sejam estragados" e a de que os pais nunca estejam errados ou nunca devam demonstrar isto a seus filhos. Esta forma de pensar não descreve a realidade, pois a admissão, pelos pais, de próprios erros, não prejudica a educação; ao contrário, ensina os filhos, por modelação (pais como modelo de comportamento) a admitirem os próprios erros e pedir desculpas quando necessário. No entanto, para promoverem, em seus filhos, habilidades de desculpar-se, os pais tendem a punir a criança quando ela não pede desculpas, além de privá-la de modelo adequado à promoção deste comportamento.

É possível concluir que o ambiente familiar pode tanto promover comportamentos socialmente adequados, como favorecer o surgimento e/ou manutenção de comportamentos inadequados. Problemas de comportamento podem ser impeditivos de aquisição de habilidades sociais, pois, como afirmam Pacheco e Gomes (1999), o comportamento agressivo pode ocorrer em função da ausência de alternativas no repertório comportamental do indivíduo. Barnett (1997) também aponta que psicopatologias surgem frente ao uso de punições e negligência, o que permite a conclusão de que a falta de HSE nos pais, que os levem a usar práticas punitivas na educação dos filhos, pode favorecer o surgimento de psicopatologias e problemas de comportamento. Diante desta perspectiva, torna-se imprescindível o estudo da criança com problema de comportamento dentro do seu contexto familiar, cujo distúrbio pode ser função de déficits de comportamentos próprios e/ou de seus pais.

Por outro lado, Silva (2000) verificou, ao comparar relatos de pais e de professores quanto a comportamentos adequados e inadequados de crianças referidas como tendo problemas de comportamento (IPC) ou comportamentos socialmente adequados (ICSA), que ambos os grupos de crianças apresentavam grande número de comportamentos adequados, apesar de o grupo IPC possuir um maior número de comportamentos inadequados. Com base nestes dados, é possível hipotetizar que crianças, mesmo as consideradas como tendo problemas de comportamento, podem ter algum repertório adequado, o qual acaba passando despercebido por pais e/ou professores, levando a um fortalecimento de comportamentos inadequados e a um enfraquecimento de comportamentos socialmente adequados.

Nesta direção, Marques (1999) oferece um exemplo de pesquisa envolvendo a análise de competência social no âmbito das relações pais-filhos. A autora investigou relações entre competência social, empatia e representação de apego junto a 100 crianças e 30 mães. Esta população foi considerada em risco, por morar em locais com alto índice de tráfico de drogas e violência e por possuir nível sócio-econômico baixo, na cidade de Porto Alegre. Alguns resultados apontam relações entre relacionamento positivo mãe-criança e: a) autoeficácia da criança e b) sentimentos de felicidade e pertencimento e comportamentos socialmente competentes da criança. Estes resultados mostram que HSE dos pais podem favorecer comportamentos socialmente adequados nos filhos, à medida que podem desenvolver maior auto-eficácia e sentimentos de felicidade e melhor desempenho acadêmico e social. Tais sentimentos podem ser desenvolvidos em ambientes familiares mais afetivos que punitivos.

Implicações do campo teórico-prático do treinamento em habilidades sociais (THS) e das habilidades sociais educativas de pais (HSE) para a prevenção el ou remediação de problemas de comportamento 
Na literatura, em especial a norte-americana, são encontrados diversos programas para pais (por exemplo Becker, 1974; Webster-Stratton, 1985; Calvert \& McMahon, 1987; Webster-Stratton, 1989; McMahon, 1996) como tentativas de resolver problemas, tais como desobediência, agressividade e desatenção dos filhos. Os programas necessitam esclarecer que o controle dos pais sobre os filhos não pode estar acima dos direitos da criança de se expressar, defender-se e dar opiniões, ou seja, as inter-relações devem ser pautadas pelo equilíbrio de reforçadores, permitindo a expressão de todos os membros familiares e favorecendo melhor comunicação e resolução de problemas. A seguir são apresentados alguns treinamentos para pais a fim de analisálos à luz do THS e das HSE.

Como não é objetivo deste trabalho realizar uma revisão da literatura quanto a programas para pais, são apresentadas, a seguir, algumas meta-análises, bem como alguns relatos de intervenções, a título de ilustração.

\section{Meta-análises}

Serketich e Dumas (1996) fizeram uma meta-análise de 26 treinamentos para pais de crianças com problemas de comportamento. Os autores afirmam que o primeiro treinamento comportamental para pais foi realizado por Hanf (1969) e utilizou procedimentos como instrução didática (reforçamento diferencial e time-out), modelação e role-playings, os quais foram sendo implementados em diversos programas de intervenção. No entanto, os efeitos e a manutenção dos resultados eram limitados frente a características demográficas adversas, tais como desemprego e baixa renda familiar; conflitos conjugais; psicopatologias (por exemplo depressão); drogadição e alcoolismo. Nesta meta-análise os pesquisadores verificaram que os tratamentos possuíam, em média, 9,53 sessões e a média de idade das crianças era de 6 anos. Todos os estudos analisados, ao comparar grupos controle e experimental, mostraram resultados positivos (aproximadamente $80 \%$ ) quanto ao ajustamento das crianças, que se mantiveram apenas a curto prazo. Porém, os programas mais efetivos foram os realizados com amostras pequenas de pais com filhos em torno de 10 anos. Segundo Serketich e Dumas (1996) apenas $22 \%$ dos estudos utilizavam grupos controles adequados, dificultando conclusões quanto à efetividade e à generalização dos resultados.

Na mesma direção, Forehand e Kotchick (1996) fizeram uma revisão sobre treinamentos para pais em duas revistas: Behavior Therapy e Journal of Consulting and Clinical Psychology, de 1970 a 1994. Os autores afirmam que os treinamentos para pais decresceram nas últimas décadas e alertam para a necessidade de reconhecer a importância da cultura, pois valores desta ordem interferem nas intervenções para pais de crianças com problemas de comportamento. Com a revisão, os pesquisadores concluíram que os treinamentos para pais os ajudam a manejar e reduzir problemas de comportamento, inclusive, considerando, às vezes, as variáveis estrutura familiar (por exemplo, casado x divorciado) e psicopatologias parentais.
Webster-Stratton (1997) faz uma análise de diversos programas para pais de crianças com problemas de comportamento e conclui que muitos estudos têm sido realizados com pais com intuito de resolver problemas de comportamento de seus filhos. Entretanto, nas avaliações de seguimento os resultados favoráveis são mantidos para alguns pais e não para outros, indo na direção dos achados de Serketich e Dumas (1996). Segundo a pesquisadora, fatores cognitivos (definidos como a percepção dos pais sobre o comportamento do filho), psicológicos e de ajustamento conjugal podem ser responsáveis pelo sucesso ou fracasso do programa para pais, sendo o sucesso visto como a mudança de atitude e de comportamento dos pais e mudança comportamental da criança.

Para Webster-Stratton (1985) os pais que continuaram tendo, no pós-tratamento, percepção negativa do comportamento do filho, não conseguiram manter os efeitos comportamentais positivos do programa. A autora hipotetiza que pode haver um desvio nas percepções e comportamentos dos pais em relação ao comportamento dos filhos, e, assim, muitas crianças não seriam, de fato, desviantes.

Para Webster-Stratton (1985), existem vários preditores para o sucesso ou fracasso de programas para pais. Dentre eles, estão as experiências de vida, desvantagem sócio-econômica e falta de suporte social das famílias. As famílias intactas têm mais sucesso e conseguem melhor manutenção dos efeitos do tratamento que as famílias de pais separados. Diversos autores, como Webster-Stratton (1994) e Cousins e Weiss (1993) acrescentam que o sofrimento conjugal, abuso do cônjuge, falta de suporte conjugal, depressão materna e alto nível de stress também interferem nos ganhos do tratamento. Assim, para um efetivo sucesso dos programas, é preciso alterar as concepções de treinamento para pais e incluir estratégias favorecedoras de suporte social, enfrentamento de dificuldades financeiras e experiências de vida negativas. Porém, ainda faltam conhecimentos da relação entre as variáveis ambientais que podem influenciar a família e o tratamento de crianças com problema de comportamento (WebsterStratton, 1985).

\section{Exemplos de intervenções com pais}

Webster-Stratton (1994) comparou dois programas (parent group discussion and video-tape modeling - GDVM training e GDVM plus advance). O GDVM training foi composto por dez videotapes com finalidade de modelar habilidades parentais, sendo que cada videotape durava 25 minutos, os quais eram seguidos por discussão, na qual o terapeuta encorajava as idéias dos pais e a solução de problemas. $\mathrm{O}$ GDVM training abordou os seguintes temas: habilidade de brincar, elogiar e recompensar, colocar limites e lidar com comportamentos inadequados. O GDVM plus advance foi composto pelo programa GDVM, acrescentado de 6 programas de videotape sobre: a) auto controle pessoal, tais como enfrentamento de raiva, depressão e stress; b) habilidades de comunicação e formas de obter suporte, tais como ouvir ativamente e falar expressivamente; c) habilidade de resolver problemas entre adultos, estendidas aos membros da família 
e criança; d) habilidade de ensinar a criança a resolver problemas e e) fortalecimento do suporte social, pois os participantes do programa foram encorajados, em todas as sessões, a ajudarem uns aos outros. A autora verificou que o Advance foi mais efetivo, pois proporcionou melhoras significativas nas habilidades de resolução de problemas, comunicação e cooperação, maior redução de problemas de comportamento das crianças e também melhor compreensão e generalização dos conceitos aprendidos.

Webster-Stratton (1989), com intuito de comparar a satisfação de pais com filhos com problemas de comportamento, quanto a programas de treinamento para pais, comparou três diferentes métodos: a) um dos grupos era treinado a se auto-administrar videotapes em casa; b) ao segundo, era proporcionada discussão em grupo, na presença do terapeuta, porém sem videotape; e c) para o terceiro grupo eram apresentados os videotapes, com grupo de discussão dirigido pelo terapeuta. A autora verificou que os três grupos apresentaram melhoras, inclusive com seguimento de um mês e de um ano, porém os resultados foram maiores no terceiro grupo, o que permite concluir que o uso de videotapes é de extrema importância, pois mostrou-se bastante útil no fornecimento de modelos comportamentais; porém, quando utilizados na presença do terapeuta proporcionou melhores resultados.

Dishion e Patterson (1992) promoveram um treinamento para pais de crianças com diversos problemas de comportamento, os quais consistiam em agressividade, roubo e comportamento opositivo com os pais. Os autores estavam interessados em avaliar qual idade das crianças seria mais adequada para promover intervenções e assim estabeleceram dois grupos. A média do tratamento foi de 17 horas, (variando de 4 a 48 horas), havendo um tempo delimitado; no entanto, tendo como critério de duração a aquisição de habilidades treinadas. O programa para pais foi efetivo em desenvolver habilidades sociais educativas de: a) observação sistemática para relatar a ocorrência de problemas de comportamentos e de comportamentos pró-sociais; b) recompensar comportamentos pró-sociais e utilizar time-out para comportamentos antisociais e c) resolução de problemas, negociação e estabelecimento de contratos pais-filhos.

Rocha e Brandão (1997) propõem um programa para pais brasileiros, com quatro etapas. Na primeira, os pais falam sobre os filhos, em geral sobre os comportamentos com os quais não sabem lidar. Num segundo momento, o manejo terapêutico está em fazer com que os pais reconheçam a influência que exercem no comportamento dos filhos, falando sobre as interações pais-filhos, aumentando as verbalizações sobre si mesmos e diminuindo as referentes aos filhos. Na terceira etapa do trabalho é solicitado dos pais que falem sobre si mesmos, ou seja, que relatem comportamentos abertos e encobertos e suas influências nos comportamentos dos filhos. Finalmente, na última etapa, os pais aprendem a estabelecer novas contingências, realizando análises funcionais dos próprios comportamentos, como dos comportamentos dos filhos, diferenciando aqueles comportamentos que promovem repertório adequado e os que promovem comportamentos inadequados nas crianças. Segundo os autores, este trabalho não consiste somente de orientações, conselhos ou estabelecimento de comportamentos específicos; trata-se de uma intervenção que proporciona aos pais, por meio de discussões grupais, um entendimento real de seus comportamentos e das contingências atuais que os determinam e os mantém no relacionamento com os filhos. Esta maneira de intervir pode ser útil para desenvolver auto-consciência nos pais sobre as contingências que mantêm seus comportamentos, favorecendo, assim, mudanças satisfatórias.

Marinho (1999) promoveu um treinamento para pais de crianças brasileiras com idades entre 7 e 12 anos que apresentavam diversos problemas de comportamento. A intervenção durou 12 sessões, de aproximadamente 90 minutos, e foi composta por três fases: a) atenção diferencial (5 sessões), em que os pais foram ensinados a atentar e reagir diferencialmente para os comportamentos adequados e inadequados dos filhos; b) treino em solução de problemas (5 sessões), para que os pais pudessem realizar adequadamente análises funcionais e elaborar planos de ações e c) assuntos diversos ( 2 sessões), para discutir assuntos de interesse dos pais, tais como sexualidade, drogas e religião. O programa foi efetivo em desenvolver habilidades sociais educativas nos pais, tais como resolução de problemas, que os ajudaram a reduzir comportamentos delinqüentes e agressivos dos filhos.

Ainda, na literatura brasileira, Silva, Del Prette e Del Prette (2000) avaliaram a efetividade de um programa, de natureza preventiva, para pais. $\mathrm{O}$ treinamento em habilidades sociais para pais foi realizado em dez sessões, duas vezes por semana, com duração aproximada de uma hora e meia cada. A primeira e a última sessão foram utilizadas para avaliações pré e pós-treinamento. No programa foram utilizadas técnicas usuais da área de análise do comportamento, tais como modelação, feedback, video-feedback, reforçamento diferencial, modelagem, tarefas para casa, etc. Foram treinadas as seguintes Habilidades Sociais Educativas: leitura ambiental (observar, escutar, interpretar comportamentos, iniciar e manter conversação com os filhos, adequar a própria fala à compreensão do filho, expressar amor, afeto e agrado ao(s) filho(s), defender os próprios direitos em relação ao(s) filho(s), incentivar a emissão adequada de comportamentos pelo(s) filho(s), dar feedback ao comportamento emitido adequadamente pelo(s) filho(s), controlar as próprias emoções, verbalizar e aplicar conceitos de assertividade, não-assertividade e agressividade, solicitar favores, recusar pedidos não razoáveis do(s) filho(s), expressar as próprias opiniões, inclusive as de desagrado, dar ordens curtas e claras ao(s) filho(s), pedir mudança no comportamento do(s) filho(s), lidar com críticas recebidas pelo(s) filho(s), respeitar opiniões e direitos do(s) filho(s), desculpar-se com o(s) filho(s), ignorar comportamento inadequado emitido pelo(s) filho(s). O programa mostrou-se efetivo em desenvolver habilidades essenciais para promover o relacionamento positivo entre pais e filhos e uma educação efetiva, tais como realizar leitura ambiental, consequenciar positivamente comportamentos adequados 
dos filhos e expressar sentimentos positivos de afeto e carinho. No entanto, os pais relataram as dificuldades em deixar o uso de punições e em expressar adequadamente sentimentos negativos, mas demonstraram ter consciência de tais dificuldades e estarem esforçando-se para superá-las. Este estudo alertou para a importância de pesquisas de levantamento, no contexto brasileiro, para um melhor entendimento das práticas educativas e das relações entre os comportamentos dos pais e dos filhos.

Ao analisar, de maneira global, trabalhos realizados com pais é possível obter algumas conclusões: a) a maioria dessas intervenções foi conduzida em grupo (por exemplo, Marinho, 1999; Rocha \& Brandão, 1997; Silva, Del Prette \& Del Prette, 2000 e Webster-Stratton, 1994); b) diversas habilidades foram promovidas nos repertórios de pais, tais como "resolução de problemas" (por exemplo, Marinho, 1999; McMahon, 1996; Silva, Del Prette \& Del Prette, 2000 e Webster-Stratton, 1994), "elogios/recompensas" (por exemplo, McMahon, 1996; Marinho, 1999, Silva, Del Prette \& Del Prette, 2000; Brestan, Jacobs, Rayfield \& Eyberg, 1999, Ruma, Burke \& Thompson, 1996 e Webster-Stratton, 1994), "experiência de autocontrole pessoal", envolvendo o tratamento de depressão, controle de raiva e stress (Webster-Stratton, 1994), "habilidades de comunicação" (por exemplo, Silva, Del Prette \& Del Prette, s.d. e Webster-Stratton, 1994) e "fortalecimento de suporte social" (Webster-Stratton, 1994); c) diversas técnicas foram utilizadas, entre elas a modelação por meio de role-playing (por exemplo, Silva, Del Prette \& Del Prette, 2000, Adams \& Kelley, 1992 e Webster-Stratton, 1994) e de videotapes (por exemplo, Silva, Del Prette \& Del Prette, 2000, Ruma, Burke \& Thompson, 1996 e Webster-Stratton, 1994) que pareceram ser viáveis para a efetividade das intervenções com pais.

As intervenções promovem, nos pais, HSE essenciais para a redução de comportamentos inadequados e aumento de adequados, tais como monitoramento, reforçamento positivo, atenção aos comportamentos adequados. Silva, Del Prette e Del Prette (2000) apontam como essenciais a promoção de habilidades sociais, tais como expressão de afeto, carinho, opiniões e direitos, que favorecem uma educação efetiva e um relacionamento positivo entre pais e filhos. Estas HSE aproximam pais e filhos, favorecem um clima amigável e de cooperação, podendo prevenir o surgimento de problemas de comportamento, ao mesmo tempo que aumentam a chance de que resultados da intervenção mantenham-se a longo prazo. Certamente, como afirma Webster-Stratton (1985), se os programas puderem também desenvolver, nos pais, suporte para enfrentamento de dificuldades financeiras e experiências de vida negativas, é possível que os mesmos se tornem mais efetivos.

O presente artigo procurou tecer considerações entre a prática educativa de pais e problemas de comportamento de filhos, à luz do referencial teórico-prático do treinamento em habilidades sociais. Intervenções com pais, com a finalidade de promover habilidades sociais educativas são imprescindíveis à prevenção e à redução de problemas de comportamento em crianças, de forma a evitar dificuldades escolares e de socialização na meninice e, desta forma, também prevenir a delinquiência juvenil.

\section{Referências}

Adams, C. D., \& Kelley, M. L. (1992). Managing sibling aggression: Overcorrection as an alternative to time-out. Behavior Therapy, 23, 707717.

Alberti, R. E., \& Emmons, M. L. (1978). Comportamento assertivo: um guia de auto-expressão. Belo Horizonte: Interlivros.

Barnett D. (1997). The effects of early intervention on maltreating parents and their children. In M. J. Guralnick (Org.), The effectiveness of early intervention (pp. 147-453). Baltimore: Paul H. Brookes.

Becker, W. C. (1974). Os pais são também professores. São Paulo: Editora Pedagógica e Universitárias.

Biasoli-Alves, Z. M. M. (1994). Família-socialização-desenvolvimento. Tese de Livre-docência não-publicada, Universidade de São Paulo, Ribeirão Preto.

Brestan, E. V., Jacobs, J. R., Rayfield, A. D., \& Eyberg, S. M. (1999). A consumer satisfaction measure for parent-child treatments and its relation to measures of child behavior change. Behavior Therapy, 30, 17-30.

Brioso, A., \& Sarrià, E. (1995). Distúrbios de comportamento. In C. Coll, J. Palacios \& A. Marchesi (Orgs.), Desenvolvimento psicológico e educação: necessidades educativas especiais e aprendizagem escolar (Vol. 3, pp. 157168). Porto Alegre: Artes Médicas.

Caballo, V. E. (1995). Una aportación española a los aspectos moleculares, a la evaluación y al entrenamiento de las habilidades sociales. Revista Mexicana de Psicologia, 12(2), 121-131.

Caballo, V. E. (1996). O treinamento em habilidades sociais. In V. E. Caballo (Org.), Manual de técnicas de terapia e modificação do comportamento (pp. 361-398). São Paulo: Santos.

Caballo, V. E. (1997). El papel de las habilidades sociales en el desarrollo de las relaciones interpersonales. In D. R. Zamignani (Org.), Sobre comportamento e cognição (Vol. 3, pp. 229-233). São Paulo: ARBytes.

Calvert, S. C., \& McMahon, R. J. (1987). The treatment acceptability of a behavioral parent training program and its components. Behavior Therapy, $2,165-179$.

CID-10 (1993). Classificação de transtornos mentais e de comportamento da CID-10: Descrições clínicas e diretrizes diagnósticas. Porto Alegre: Artes Médicas.

Conte, F. C. (1997). Promovendo a relação entre pais e filhos. In M. Delitti (Org.), Sobre comportamento e cognição (Vol. 2, pp. 165-173). Santo André: ARBytes.

Cousins, L. S., \& Weiss, G. (1993). Parent training and social skills training for children with attention-deficit hyperactivity disorder: How can they be combined for greater effectiveness? Canadian Journal of Psychiatry, 38, 449-457.

Del Prette, A., Del Prette, Z. A. P., \& Branco, U. V. C. (1992). Competência social na formação do psicológo. Paidéia, 2, 40-50.

Del Prette, Z. A. P., \& Del Prette, A. (1996). Habilidades sociais: uma área em desenvolvimento. Psicologia: Reflexão e Crítica, 9(2), 287-389.

Del Prette, Z. A. P., \& Del Prette, A. (1999). Psicologia das habilidades sociais: terapia e educação. Petrópolis: Vozes.

Dishion, T. J., \& Patterson, G. R. (1992). Age effects in parent training outcome. Behavior Therapy, 23, 719-729.

Falcone, E. M. de O. (1998). Grupos. In B. Rangé (Org.), Psicoterapia comportamental e cognitiva: pesquisa, prática, aplicações e problemas (pp. 159-169). Campinas: Editorial Psy.

Forehand, R., \& Kotchick, B. A. (1996). Cultural diversity: A wake-up call for parent training. Behavior Therapy, 27, 187-206.

Ingberman, Y. K. (1997). Terapia comportamental com famílias. In M. Delitti (Org.), Sobre comportamento e cognição (Vol. 2, pp. 230-236). Santo André: ARBytes. 
Kaiser, A. P., \& Hester, P. P. (1997). Prevention of conduct disorder through early intervention: A social-communicative perspective. Behavioral Disorders, 22(3), 117-130.

Kaplan, H. I., Sadock, B. J., \& Grebb, J. A. (1997). Compêndio de psiquiatria: Ciências do comportamento e psiquiatria clínica $\left(7^{\underline{\mathrm{a}}}\right.$ ed.). Porto Alegre: Artes Médicas.

Marinho, M. L. (1999). Comportamento infantil anti-social: Programa de intervenção junto à família. In R. R. Kerbauy \& R. C. Wielnska (Orgs.), Sobre comportamento e cognição: Psicologia comportamental e cognitiva-da reflexão teórica à diversidade na aplicação (Vol. 4, pp. 207-215). Santo André: ARBytes.

Marques, A. L. (1999). Competência social, empatia e representação mental da relação de apego em famílias em situação de risco. Dissertação de Mestrado não-publicada, Universidade Federal do Rio Grande do Sul, Porto Alegre.

Marturano, E. M., Linhares, M. B. M., \& Parreira, V. L. C. (1993). Problemas emocionais e comportamentais associados a dificuldades na aprendizagem escolar. Medicina Ribeirão Preto, 26(2), 161-175.

McFall, R. M. (1982). A review and reformulation of the concept of social skills. Behavioral Assessment, 4, 1-33.

McMahon, R. J. (1996). Treinamento de pais. In V. E. Caballo (Org.), Manual de técnicas de terapia e modificação do comportamento (pp. 397-424). São Paulo: Santos.

Pacheco, J. T. B., \& Gomes, W. B. (1999). Estilos parentais e o desenvolvimento de habilidades sociais na adolescência [Resumos]. In Sociedade Brasileira de Psicologia (Org.), XXIX Reunião Anual de Psicologia. Resumos (pp. 124-125). Campinas, SP: Autor.

Patterson, G. R., DeBaryshe, B. D., \& Ramsey, E. (1989). A developmental perspective on antisocial behavior. American Psychologis, 44 (2), 329-335.

Rocha, M. M., \& Brandão, M. Z. da S. (1997). A importância do autoconhecimento dos pais na análise e modificação de suas interações com os filhos. In M. Delitti (Org.), Sobre comportamento e cognição (Vol. 2, pp. 137-146). São Paulo: ARBytes Editora.

Ruma, P. R., Burke, R. V., \& Thompson, R. W. (1996). Group parent training: Is it effective for children of all ages? Behavior Therapy, 27, 159-169.
Serketich, W. J., \& Dumas, J. E. (1996). The effectiveness of behavioral parent training to modify antisocial behavior in children: A meta-analysis. Behavior Therapy, 27, 171-186.

Sidman, M. (1995). Coerção e suas implicações. Campinas: Editorial Psy II.

Sigolo, S. R. R. L. (1986). Análise das práticas de educação utilizadas com crianças portadoras de necessidades educativas especiais mental de 2 a 4 anos. Dissertação de Mestrado não-publicada, Universidade Federal de São Carlos, São Carlos.

Silva, A. T. B. (2000). Problemas de comportamento e comportamentos socialmente adequados: sua relação com as habilidades sociais educativas de pais. Dissertação de Mestrado não-publicada, Universidade Federal de São Carlos, São Carlos.

Silva, A. T. B., Del Prette, A., \& Del Prette, Z. A. P. (2000) Relacionamento pais-filhos: um programa de desenvolvimento interpessoal em grupo. Psicologia Escolar e Educacional, 3(3), 203-215.

Skinner, B. F. (1993). Ciência e comportamento humano (8a ed.) São Paulo: Martins Fontes. (Texto original publicado em 1953).

Trivelatto, M. de C., \& Marturano, E. M. (1999). Crianças com problemas de comportamento associadas a dificuldades de aprendizagem: Um estudo do ambiente familiar[Resumos]. In Sociedade Brasileira de Psicologia (Org.), XXIX Reunião Anual de Psicologia. Resumos (pp. 178-179). Campinas, SP: Autor.

Webster-Stratton, C. (1985). Case studies and clinical replication series: Predictors of treatment outcome in parent training for conduct disordered children. Behavior Therapy, 16, 223-243.

Webster-Stratton, C. (1989). Systematic comparison of consumer satisfaction of three cost-effective parent training programs for conduct problem children. Behavior Therapy, 20, 103-115.

Webster-Stratton, C. (1994). Advancing videotape parent training: A comparison study. Journal of Consulting and Clinical Psychology, 62(3), 583-593.

Webster-Stratton, C. (1997). Early intervention for families of preschool children with conduct problems. In M. J. Guralnick (Org.), The effectiveness of early intervention (pp. 429-453). Baltimore: Paul H. Brookes.

Alessandra Turini Bolsoni-Silva, doutoranda pelo Programa de Pós-Graduação em Psicologia, da Faculdade de Filosofia, Ciências e Letras (FFCL) da Universidade de São Paulo (USP - Campus Ribeirão Preto), sob orientação da segunda autora e mestre em Educação Especial (Universidade Federal de São Carlos - UFSCar), é Professora Assistente do Departamento de Psicologia da Faculdade de Ciências da Universidade Estadual Paulista (UNESP - Campus Bauru).

Endereço para correspondência: Eng. Luiz Edmundo C. Coube, s/n, 17.033.360, Bauru, S. P. Fone: (14)221.6087. E-mail: bolsoni@fc.unesp.br.

Edna Maria Marturano, doutora em Psicologia pela Universidade de São Paulo, é Professora Titular do Departamento de Neurologia, Psiquiatria e Psicologia Médica da Faculdade de Medicina de Ribeirão Preto da Universidade de São Paulo (USP) e orientadora do Programa de Pós-Graduação em Psicologia, da Faculdade de Filosofia, Ciências e Letras (FFCL) da Universidade de São Paulo (USP - Campus Ribeirão Preto). 